\title{
Effects of Sporidiobolus pararoseus Y16 on Postharvest Blue Mold Decay and the Defense Response of Apples
}

\author{
Lina Zhao, ${ }^{1}$ Yiwen Sun, ${ }^{1}$ Dongbiao Yang, ${ }^{2}$ Jun Li, ${ }^{3}$ Xiangyu Gu, \\ Xiaoyun Zhang, ${ }^{1}$ and Hongyin Zhang $\mathbb{B}^{1}$ \\ ${ }^{1}$ School of Food and Biological Engineering, Jiangsu University, Zhenjiang, Jiangsu 212013, China \\ ${ }^{2}$ Beilun Entry-Exit Inspection and Quarantine Bureau, Ningbo, Zhejiang 315800, China \\ ${ }^{3}$ School of the Environment and Safety Engineering, Jiangsu University, Zhenjiang, Jiangsu 212013, China \\ ${ }^{4}$ School of Grain Science and Technology, Jiangsu University of Science and Technology, Zhenjiang, Jiangsu 212003, China \\ Correspondence should be addressed to Hongyin Zhang; zhanghongyin126@126.com
}

Received 14 November 2017; Accepted 11 February 2018; Published 29 March 2018

Academic Editor: Alejandro Hernández

Copyright (c) 2018 Lina Zhao et al. This is an open access article distributed under the Creative Commons Attribution License, which permits unrestricted use, distribution, and reproduction in any medium, provided the original work is properly cited.

\begin{abstract}
The efficacy of Sporidiobolus pararoseus Y16 in controlling postharvest blue mold caused by Penicillium expansum on apples and the defense response involved were evaluated. The results suggested that the decay incidence of blue mold of apples treated by $S$. pararoseus Y16 was significantly reduced compared with the control. In vitro testing indicated that germination of spores and germ tube length of $P$. expansum were markedly inhibited by $S$. pararoseus Y16. Meanwhile, polyphenol oxidase (PPO), peroxidase (POD), phenylalanine ammonia lyase (PAL), and catalase (CAT) activities and several pathogenesis-related (PR) gene expression levels (including PR3, PR4, PR5, and PR9) were determined. In apples, the activities of PPO, POD, CAT, and PAL were significantly induced by $S$. pararoseus Y16 treatment compared with the control fruits. The relative expression levels of PR3 and PR4 were significantly induced at 4 and $6 \mathrm{~d}$, while $P R 5$ was significantly induced at 4 and $6 \mathrm{~d}$ and $P R 9$ was significantly induced at $4 \mathrm{~d}$. Therefore, the reduction in apple fruit decay by $S$. pararoseus Y16 treatment could be related to the increased activities of related enzymes and proteins involved in the defense against pathogens, which suggest that $S$. pararoseus Y16 is a potential antagonistic yeast.
\end{abstract}

\section{Introduction}

In general, postharvest losses of fruits and vegetables pose enormous problem worldwide [1], ranging from 10 to $30 \%$ in developed countries and even more losses in developing countries [2]. Apples are among the most commonly consumed fruits, which provided fresh ones throughout the year [3] and are one of the most important fruits produced in China and other countries. A significant proportion of postharvest losses are attributed to microbiological diseases caused by fungal pathogens limiting the storage life of apples. Blue mold decay caused by Penicillium expansum and grey mold decay caused by Botrytis cinerea are two of the most important postharvest diseases of apples [4, 5], which lead to serious economic losses in storage and transportation, especially, blue mold decay caused by $P$. expansum, which may lead to patulin accumulation in apples.

There are many methods to control the postharvest diseases and increase the shelf life of fruits. Nowadays, the use of synthetic fungicides can effectively control pathogens of postharvest fruits and vegetables as the primary strategy. However, there is an increased concern about the potential harmful effects on human health and environment by fungicide residues [6]. Therefore, under the current circumstances, it is necessary to develop alternative methods for synthetic chemicals.

Biological control with antagonistic yeasts has emerged as a promising way to reduce synthetic fungicide usage [7]. Many microbial antagonists have been reported to control several pathogens on different fruits and vegetables [8]. In 
this regard, the use of antagonistic yeasts was reported to have a significant effect on blue mold decay in apples, including Pichia caribbica [4], Pantoea agglomerans [9], Rhodotorula mucilaginosa [10], and Rhodosporidium paludigenum [11]. Although several antagonistic yeasts were reported to have significant effect on blue mold decay of apples, the effectiveness of biological control also needs to be further improved. Sporidiobolus pararoseus Y16, which was isolated by our laboratory from the surfaces of grape leaves picked in unsprayed orchards [12], could significantly inhibit Aspergillus niger decay of table grapes [13], while there is no information regarding studying biocontrol of postharvest diseases of apple fruits by $S$. pararoseus Y16, and the mechanism of $S$. pararoseus controlling of postharvest diseases is not yet clear.

In this paper, $S$. pararoseus Y16 which was isolated by our laboratory from the surfaces of grape leaves picked in unsprayed orchards was chosen as the study subject. The object of this study was to evaluate the efficacy of $S$. pararoseus against $P$. expansum infection in apples and determine (1) the efficacy of $S$. pararoseus Y16 in controlling of blue mold on apples, (2) the population dynamics of S. pararoseus Y16 in apple wounds, (3) the effectiveness of $S$. pararoseus Y16 against pathogens in vitro, and (4) the effect of $S$. pararoseus Y16 on activities of defense-related enzymes and related gene expressions levels.

\section{Materials and Methods}

2.1. Antagonist. S. pararoseus Y16 was isolated by our laboratory from the surfaces of grape leaves picked in unsprayed orchards, Zhenjiang, China, and maintained at $4^{\circ} \mathrm{C}$ on nutrient yeast dextrose agar (NYDA: $8 \mathrm{~g} / \mathrm{L}$ nutrient broth, $5 \mathrm{~g} / \mathrm{L}$ yeast extract, $10 \mathrm{~g} / \mathrm{L}$ dextrose, and $20 \mathrm{~g} / \mathrm{L}$ agar) [14]. The yeast strain was preserved in the China General Microbiological Culture Collection Center, and the number was CGMCC 2.5351. The yeast was grown in $250 \mathrm{~mL}$ Erlenmeyer flasks containing $50 \mathrm{~mL}$ of nutrient yeast dextrose broth (NYDB: $8 \mathrm{~g} / \mathrm{L}$ nutrient broth, $5 \mathrm{~g} / \mathrm{L}$ yeast extract, and $10 \mathrm{~g} / \mathrm{L}$ dextrose). Flasks were incubated on a rotary shaker at $180 \mathrm{rpm}$ for $20 \mathrm{~h}$ at $28^{\circ} \mathrm{C}$. Following incubation, cells were centrifuged at $7500 \times \mathrm{g}$ for $10 \mathrm{~min}$ and washed twice with sterile distilled water in order to remove the growth medium. Cell pellets were resuspended in sterilized distilled water and adjusted to the required concentration by a hemocytometer (XB-K250, Jianling Medical Device Company, Danyang, China). Cell concentration was then adjusted as needed for different experiments.

2.2. Fungal Pathogen. P. expansum (preserved in the CGMCC, number 3.3703) was isolated from decayed apples and inoculated on potato dextrose agar medium (PDA: $200 \mathrm{~mL}$ of extract from boiled potatoes, $20 \mathrm{~g}$ dextrose, $20 \mathrm{~g}$ agar, and $800 \mathrm{~mL}$ distilled water). PDA plates were incubated at $25^{\circ} \mathrm{C}$ for 7 days and then transferred to $4^{\circ} \mathrm{C}$ before use. Spore suspensions were prepared by removing the spores from the sporulating edges of PDA culture with inoculating loop and suspended in sterile distilled water. Spore concentrations were adjusted as required to $5 \times 10^{4}$
spores/mL in sterile distilled water by a hemocytometer (XB-K-250, Jianling Medical Device Co., Danyang, China).

2.3. Fruits. Apples (M. domestica Borkh, cv. Fuji) were harvested at commercial maturity from an orchard in Yantai, Shandong province, and selected for uniformity of size, ripeness, and absence of apparent injury or infection. Fruits were selected randomly and sterilized with $0.1 \%$ sodium hypochlorite for $1 \mathrm{~min}$, washed with tap water, and allowed to air-dry at room temperature.

2.4. Effect of S. pararoseus on Blue Mold of Apple Fruit. Three uniform wounds ( $5 \mathrm{~mm}$ diameter and $3 \mathrm{~mm}$ depth) were made at the equator of each apple fruit using a sterile borer. $30 \mu \mathrm{L}$ of cell suspensions of $S$. pararoseus $\mathrm{Y} 16$ at $10^{6}, 10^{7}$, $10^{8}$, and $10^{9}$ cells $/ \mathrm{mL}$ were pipetted into each wound site, respectively, and sterile distilled water was used as the control. Two hours later, $30 \mu \mathrm{L}$ of suspension of $P$. expansum $\left(5 \times 10^{4}\right.$ spores $/ \mathrm{mL}$ ) was inoculated into each wound. The apples were stored in enclosed plastic trays at $20^{\circ} \mathrm{C}$ with $95 \% \mathrm{RH}$. The decay incidence and lesion diameter of apples were recorded after 6 days of incubation. There were three replicates of twelve fruits for each treatment. All treatments were arranged in a randomized complete block design, and the experiment was conducted twice.

2.5. Population Dynamics of S. pararoseus in Apple Wounds. Apples were prepared and wounded as described above. The method to evaluate the population studies of $S$. pararoseus Y16 in apple wounds was according to [15] with some modifications. Each wound on apple was inoculated with $30 \mu \mathrm{L}$ of $S$. pararoseus Y16 $\left(10^{8}\right.$ cells $\left./ \mathrm{mL}\right)$, and then apples were stored at $20^{\circ} \mathrm{C}$ and $4^{\circ} \mathrm{C}$, respectively. The tissue of apple wound was removed with a sterile knife and macerated in $50 \mathrm{~mL}$ of sterile $0.85 \%$ sodium chloride solution and quartz sand in a mortar. The amount of $S$. pararoseus Y16 was recovered from the wounds after incubation at $20^{\circ} \mathrm{C}$ for 0 (1 h after treatment), 1, 2, 3, 4, 5, 6, 7, and 8 days and at $4^{\circ} \mathrm{C}$ for 0 (1 h after treatment), 3, 6, 9, 12, 15, 18, 21, and 23 days, respectively. 10 -fold serial dilutions were made and $100 \mu \mathrm{L}$ of each dilution was spread by coated rod on the NYDA plates, stored in incubator at $28^{\circ} \mathrm{C}$ for 48 hours, and then expressed as the $\log _{10} \mathrm{CFU}$ per wound. There were three replications of each treatment, and the entire experiment was repeated twice.

2.6. Effects of S. pararoseus Y16 on Spore Germination and Germ Tube Length of P. expansum In Vitro. Spores of $P$. expansum and $S$. pararoseus suspensions were prepared as described above. $100 \mathrm{~mL}$ Erlenmeyer flasks with $20 \mathrm{~mL}$ PDB were prepared with the treatment of $1 \mathrm{~mL}$ suspension of $S$. pararoseus Y16 $\left(10^{8}\right.$ cells $\left./ \mathrm{mL}\right)$ and $1 \mathrm{~mL}$ of sterile distilled water was added as the control; $1 \mathrm{~mL} P$. expansum spore suspension (adjusted to the final concentration of $10^{6}$ spores $/ \mathrm{mL}$ ) was added to each PDB flask, respectively. All flasks were incubated in rotary shaker at $75 \mathrm{rpm}$ and cultured at $28^{\circ} \mathrm{C}$ for $12 \mathrm{~h}$. The effects of S. pararoseus Y16 on spore germination and germ tube length of $P$. expansum were measured according to the method described by [14]. There were three replicates per treatment and the experiment was conducted twice. 
TABLE 1: Primer design of pathogenesis-related genes in apples.

\begin{tabular}{lcc}
\hline Unigenes & $\begin{array}{c}\text { Forward primer }\left(5^{\prime} \text { to } 3^{\prime}\right) \\
\left.\text { Reverse primer( } 5^{\prime} \text { to } 3^{\prime}\right)\end{array}$ & Gene description \\
\hline LOC 103419198 & F: TGACACATACTGCGATACAAG & Chitinase 4-like \\
R: ACAGGACGGACATTGGTTAT & $(P R)$ \\
LOC 103434169 & F: GCCACATACCACCTCTAC & Pathogenesis-related \\
protein $(P R-4)$ & Thaumatin-like protein la \\
LOC 103426173 & R: ATTCTCACCGTTGCTTGA & $(P R-5)$ \\
LOC 103403867 & F: ATGGTCTGGTCGCTTCTG & Peroxidase 51-like \\
RdActin & F: GTCAACAAGGCTAACATCGTA & $($ PR-9) \\
& R: AACTGCGTCAACGGCTGCTT & Actin \\
\hline
\end{tabular}

\subsection{Effects of S. pararoseus on Activities of Defense-Related Enzymes of Apples}

Fruit Treatment. Fruit samples were treated as described above. The wounds were then treated with $30 \mu \mathrm{L}$ suspension of S. pararoseus Y16 $\left(10^{8}\right.$ cells $\left./ \mathrm{mL}\right)$ or sterile distilled water as the control. After air drying, the apple fruits were stored in enclosed plastic trays at $20^{\circ} \mathrm{C}$ with $95 \% \mathrm{RH}$. In order to measure the activities of defense-related enzymes, the tissue surrounding each apple wound was collected at 0 ( $1 \mathrm{~h}$ after treatment), $1,2,3,4,5$, and 6 days after treatment. There were three replicates per treatment and the experiment was conducted twice.

Supernatant Extract. Two grams of tissue sample was ground with $10 \mathrm{~mL}$ of cold $\left(4^{\circ} \mathrm{C}\right)$ sodium phosphate buffer (50 mmol/L, pH 7.8) containing $1.33 \mathrm{mmol} / \mathrm{L}$ EDTA and $1 \%$ polyvinyl pyrrolidone (PVP) for peroxidase (POD), polyphenol oxidase (PPO), and catalase (CAT). The homogenates were then centrifuged at $12000 \mathrm{rpm}$ for $15 \mathrm{~min}$ at $4^{\circ} \mathrm{C}$ and the supernatants were assayed. Extraction procedures were conducted at $4^{\circ} \mathrm{C}$.

Analysis of Enzyme Activities of Apple Fruits. POD activity was assayed according to the method described by [1], and one unit was defined as an increase in $\mathrm{A}_{470}$ of 0.01 per minute. PPO activity was measured following the method described by [16], and one unit of the PPO activity was defined as the amount of the enzyme extracts producing an increase of $\mathrm{A}_{398}$ by 0.01 in $1 \mathrm{~min}$. CAT activity was determined following the method of [17], and one unit was defined as the change of $\mathrm{A}_{240}$ in 0.01 absorbance units per minute. The PAL activity was assayed as the method described by [18], and one unit of the PAL activity was defined as the formation of $1 \mu \mathrm{g}$ of cinnamic acid equivalents per hour. The POD, PPO, CAT, and PAL activities were expressed as $U$ per $g$ fresh tissue weight (U/g FW).

2.8. RNA Extraction and Real-Time-Quantitative Polymerase Chain Reaction (RT-qPCR). Apples were prepared and wounded as described above to evaluate the effect of $S$. pararoseus Y16 on activities of defense-related enzymes of apples. The apple tissue samples were removed by cold sterile knife without $S$. pararoseus Y16; three grams of tissue sample was milled using liquid nitrogen; RNA was extracted using UNlQ-10 Column Trizol Total RNA Extraction Reagent (Sangon Biotech (Shanghai, China) Co., Ltd.) according to the instruction of the manufacturer. About $1000 \mathrm{ng}$ of mRNA was used for cDNA synthesis. RT-qPCR was performed using the cDNA as template, and the gene-specific primers used were presented in Table 1.

RT-qPCR was conducted with Bio-Rad CFX-96 RealTime PCR System (Bio-Rad, USA) according to the method described by [6]. The PCR conditions were as follows: $95^{\circ} \mathrm{C}$ for $30 \mathrm{~s}, 95^{\circ} \mathrm{C}$ for $5 \mathrm{~s}, 62^{\circ} \mathrm{C}$ for $30 \mathrm{~s}$, and $72^{\circ} \mathrm{C}$ for $27 \mathrm{~s}$, followed by 40 cycles. Melting curve analyses of amplification products were performed at the end of the PCR reaction. The melting cycle was $95^{\circ} \mathrm{C}$ for $15 \mathrm{~s}, 60^{\circ} \mathrm{C}$ for $1 \mathrm{~min}, 95^{\circ} \mathrm{C}$ for $15 \mathrm{~s}$, and $62^{\circ} \mathrm{C}$ for $15 \mathrm{~s}$. The expression level was normalized to level of actin, and the results were expressed as relative expression levels; the data were quantified by the method of $2^{-\Delta \Delta C T}[6]$.

2.9. Statistical Analyses. A statistical analysis of the obtained data was carried out using SPSS 16.0 for Windows (SPSS Inc., Chicago, IL). The mean values and the standard error of the mean were calculated from the data obtained from two independent experiments. The differences between the means of the test were evaluated by Student's $t$-test and $P<$ 0.05 was considered significantly different.

\section{Results}

3.1. Effect of S. pararoseus at Different Concentrations on Blue Mold Incidence and Lesion Diameter of Apples. Efficacy of S. pararoseus Y16 at different concentrations against blue mold incidence and lesion diameter of apples were examined. Figure 1(A) showed that different concentrations of S. pararoseus Y16 significantly inhibited the decay incidence of apples compared with the control, and the higher the concentration of $S$. pararoseus Y16, the lower the decay rate. When the concentrations of $S$. pararoseus $\mathrm{Y} 16$ were $10^{8}$ and $10^{9}$ cells $/ \mathrm{mL}$, the decay rate of apples was $21.5 \%$ and $10.3 \%$, respectively. Meanwhile the decay rate of the control was $100 \%$, which indicated that $S$. pararoseus Y16 can significantly inhibit the occurrence of blue mold decay caused by $P$. expansum in apples. For lesion diameter, the same trend was observed. The 


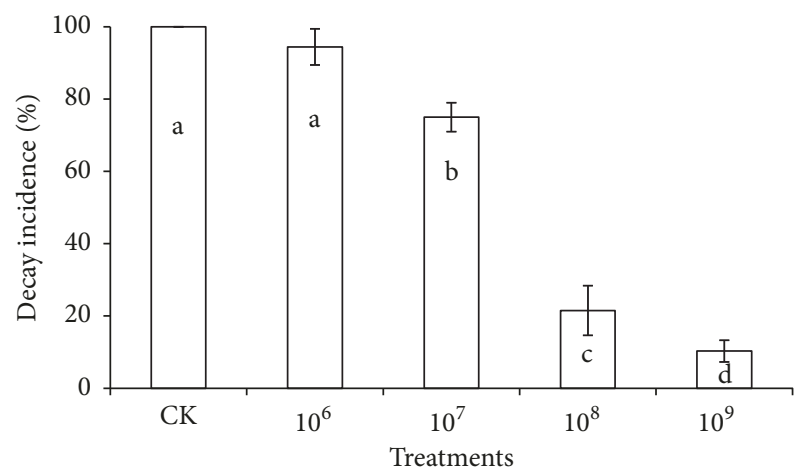

(A)

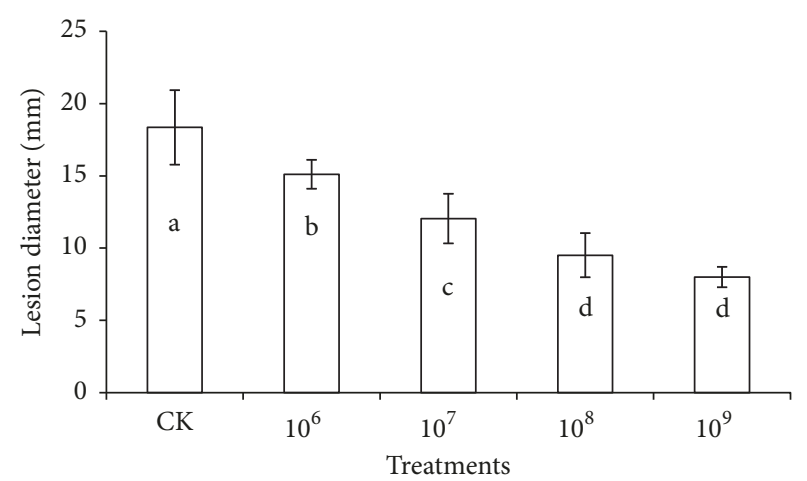

(B)

FIGURE 1: Efficacy of $S$. pararoseus Y16 in inhibiting blue mold decay of apples. Disease incidence (A) and lesion diameter (B) were measured after 6 days of (P. expansum) incubation at $20^{\circ} \mathrm{C}$. CK means control; the letters of $10^{6}, 10^{7}, 10^{8}$, and $10^{9}$ represent the concentrations of $S$. pararoseus $\mathrm{Y} 16$ at $10^{6}, 10^{7}, 10^{8}$, and $10^{9}$ cells $/ \mathrm{mL}$, respectively. Each value is the mean of two experiments. Bars represent the standard error of the mean. Data in columns with the different letters are significantly different according to Duncan's multiple range test at $P<0.05$.

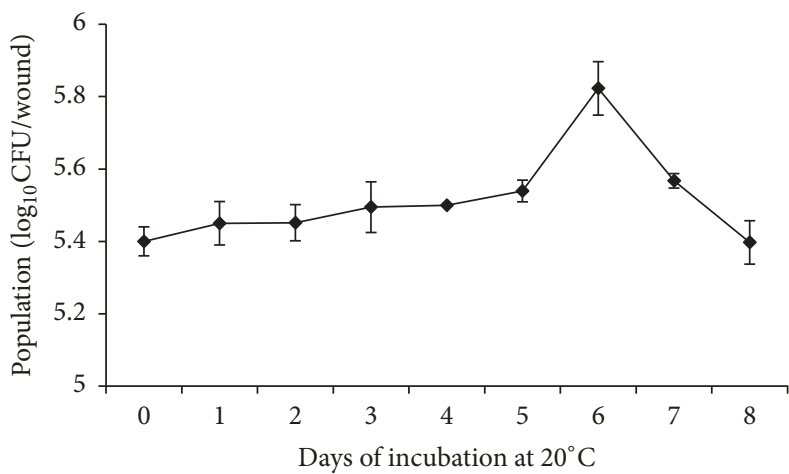

(A)

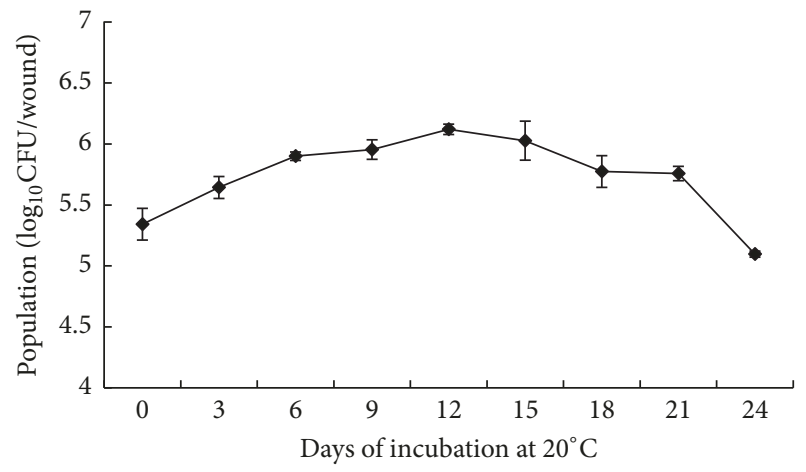

(B)

Figure 2: Population dynamics of $S$. pararoseus $\mathrm{Y} 16$ in apple wounds at $20^{\circ} \mathrm{C}(\mathrm{A})$ and $4^{\circ} \mathrm{C}(\mathrm{B})$. Bars represented standard errors.

lesion diameters of apple wounds treated with $S$. pararoseus Y16 at different concentrations $\left(10^{6}, 10^{7}, 10^{8}\right.$, and $10^{9}$ cells $\left./ \mathrm{mL}\right)$ were $15.11 \mathrm{~mm}, 12.45 \mathrm{~mm}, 9.51 \mathrm{~mm}$, and $8.03 \mathrm{~mm}$, respectively, which were significantly lower than those of the control $(18.35 \mathrm{~mm})$, and the higher concentration of $S$. pararoseus Y16, the smaller lesion diameter of the apple wounds. When the concentration of $S$. pararoseus Y16 was $10^{8}$ cells $/ \mathrm{mL}$ or $10^{9}$ cells $/ \mathrm{mL}$, the decay diameter of apple recorded the least value (Figure 1(B)).

\subsection{Population Dynamics of S. pararoseus in Apple Wounds.} Population dynamics of $S$. pararoseus Y16 in apple wounds at $20^{\circ} \mathrm{C}$ and $4^{\circ} \mathrm{C}$ were tested. The results showed that the population of $S$. pararoseus $\mathrm{Y} 16$, incubated at $20^{\circ} \mathrm{C}$, increased slowly from $1 \mathrm{~d}$ to $4 \mathrm{~d}$ and then grew quickly, from $4 \mathrm{~d}$ to $6 \mathrm{~d}$; the number of yeast in apple wounds increased by 1.09 times. The population of $S$. pararoseus Y16 reached the maximum at days 6 (Figure 2(A)). However, S. pararoseus Y16 in wounds of apple fruits stored at $4^{\circ} \mathrm{C}$ grew more slowly than those stored at $20^{\circ} \mathrm{C}$; the yeast could colonize during $0-12 \mathrm{~d}$ and then the population of the yeast decreased after $12 \mathrm{~d}$. Although the population of the yeast decreased from the $12 \mathrm{~d}$ to $24 \mathrm{~d}$, the population did not fall below $10^{5} \mathrm{CFU} /$ wound during all times points at $4^{\circ} \mathrm{C}$ (Figure $2(\mathrm{~B})$ ).

\subsection{Effects of S. pararoseus on Spore Germination and Germ} Tube Length of P. expansum In Vitro. As shown in Figure 3, $S$. pararoseus Y16 significantly decreased spore germination and germ tube length of $P$. expansum in vitro, and the higher the concentration of $S$. pararoseus Y16, the lower the spore germination rate and the germ tube length. As the concentration of yeast is $10^{8}$ cells $/ \mathrm{mL}, S$. pararoseus Y16 can inhibit spore germination totally. When treated by S. pararoseus $\mathrm{Y} 16$ of $10^{7}$ cells $/ \mathrm{mL}$, germ tube length of $P$. expansum is from $60.2 \mu \mathrm{m}$ to $8.11 \mu \mathrm{m}$ compared with the control.

3.4. Effects of S. pararoseus on PPO, POD, PAL, and CAT Activities of Apples. As indicated in Figure 4(A), treatment with $S$. pararoseus Y16 resulted in a significant increase in the PPO activity of apples compared with the control during the most storage time. At 2 days after inoculation, PPO activity of apples treated with $S$. pararoseus Y16 peaked at 1.78 times of the control. The POD activity in apples treated 


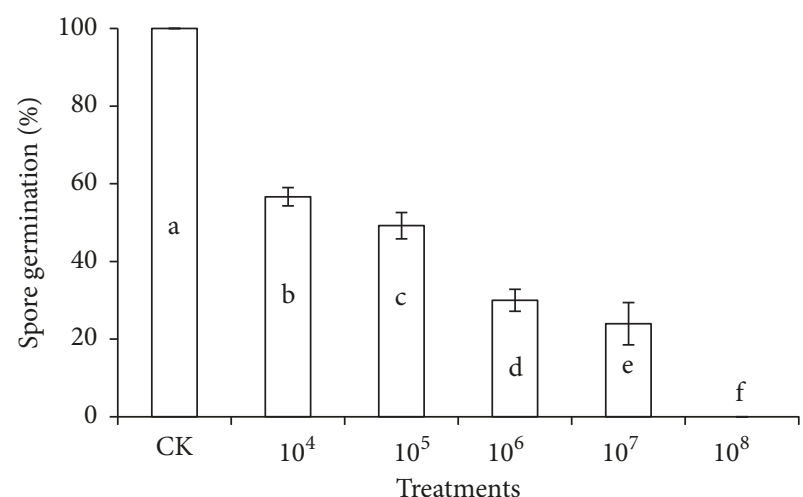

(A)

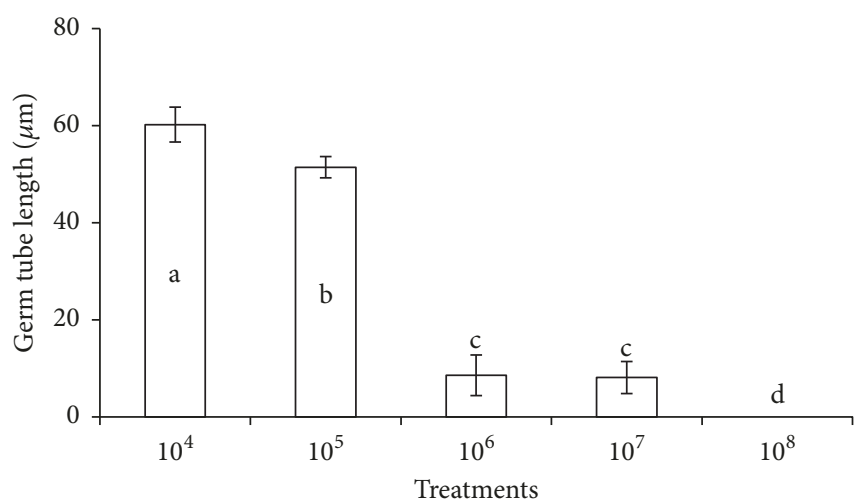

(B)

Figure 3: Effects of S. pararoseus Y16 on spore germination (A) and germ tube length (B) of P. expansum. CK means control; the letters of $10^{4}, 10^{5}, 10^{6}, 10^{7}$, and $10^{8}$ represent the concentrations of $S$. pararoseus $\mathrm{Y} 16$ at $10^{4}, 10^{5}, 10^{6}, 10^{7}$, and $10^{8}$ cells/mL, respectively. Germination rate and germ tube length were measured by microscope and micrometer after $12 \mathrm{~h}$ incubation at $28^{\circ} \mathrm{C}$ in PDB. Bars represent standard errors. Data in columns with different letters are statistically different according to Duncan's multiple range test at $P<0.05$.

with S. pararoseus Y16 increased gradually at first 3 days and reached a peak on the third day and then began to decrease. However, the POD activity in samples treated with $S$. pararoseus Y16 was still higher than the control on the whole time (Figure 4(B)). Figure 4(C) shows the CAT activity in apples for treatment with S. pararoseus Y16 and the control. The changes of CAT activity of apple fruits treated with $S$. pararoseus Y16 were similar to those of the control. However, the CAT activity of $S$. pararoseus Y16 was higher than that of the control at first 3 days, and then the difference became very small. As was shown in Figure 4(D), PAL activity of apple treated with $S$. pararoseus Y16 was higher than that of the control in the whole storage period, especially on the third day; the PAL activity of apple fruit treated with S. pararoseus Y16 was 2.31 times more than the control, reaching $4.88 \mathrm{U} / \mathrm{g}$ FW.

3.5. Effect of S. pararoseus on Defense-Related Genes of Apples. It can be seen from Figures 5(A) and 5(B) that the expression levels of $P R-3$ and $P R-4$ were induced by $S$. pararoseus Y16 at $0 \mathrm{~d}, 2 \mathrm{~d}, 4 \mathrm{~d}$, and $6 \mathrm{~d}$, respectively. Meanwhile $P R-3, P R-4$, and $P R-5$ expression levels were significantly induced at 4 and $6 \mathrm{~d}$ and $P R 9$ was significantly induced at $4 \mathrm{~d}$. The expression of $P R-4$ and $P R-5$ reached the maximum at $6 \mathrm{~d}$, while $P R-3$ and $P R-9$ reached the maximum at $4 \mathrm{~d}$. The expression levels of pathogenesis-related genes were significantly upregulated, induced by $S$. pararoseus Y16.

\section{Discussion}

The use of biocontrol agents to manage postharvest diseases of fruits and vegetables has been explored as an alternative to the use of synthetic fungicides [10]. S. pararoseus Y16 proved to be a potential biological control agent for the control of postharvest blue mold decay of apples caused by $P$. expansum in the text. However, there is no information concerning the effect of $S$. pararoseus Y16 on postharvest blue mold of apples and its mechanism involved. The object of this study was to evaluate the biocontrol efficacy of $S$. pararoseus against
P. expansum infection in apples. This is the first report of $S$. pararoseus Y16 as an antagonist of blue mold of apples.

S. pararoseus Y16 at different concentrations significantly inhibited blue mold of apples compared with the control. The higher the concentration, the better the efficacy. This finding is in agreement with $[11,19]$ that indicated that the biological control efficacy of antagonistic yeasts is dependent on the biocontrol agent's concentration and the pathogen inoculum concentration. To further understand the mechanisms of $S$. pararoseus Y16 controlled postharvest diseases of apples, we found that $S$. pararoseus could significantly inhibit the spore germination and germ tube length of $P$. expansum in in vitro experiments. Moreover, $S$. pararoseus Y16 could quickly adapt to the environment in apple wounds stored at $20^{\circ} \mathrm{C}$ or $4^{\circ} \mathrm{C}$ and kept the amount of yeast at a high level, which proved that S. pararoseus Y16 could quickly utilize the nutrients at the wounds and compete with the pathogen for space and nutrition, which explained that the disease resistance of apples was enhanced by $S$. pararoseus Y16. It can be seen that competition of space and nutrition between $S$. pararoseus Y16 and pathogen is an important reason for controlling postharvest blue mold decay of apples. Similar results for other antagonist yeasts have been reported by [20,21] who described this phenomenon as an advantage to microbial antagonists in competing for nutrients and space, which plays a major role in its biocontrol efficacy.

Furthermore, the results of our study showed that $S$. pararoseus Y16 induced higher levels of PPO, POD, CAT, and PAL activities, activating the defense mechanism of apples. Studies showed that PPO and POD are important catalytic enzymes that not only accelerate the oxidation of phenolic compounds, but also participate in the synthesis of certain hormones, while enhancing the disease resistance [22]. POD is a multifunctional enzyme, and it can be used as a good regulator of fruit aging and physiological changes. PPO activity changes the disease resistance of fruits and vegetables, which is closely related to the direct role of pathogens, and PPO also plays a protective role in the plant. CAT, which is known to control reactive oxygen scavengers (ROS) [23], 


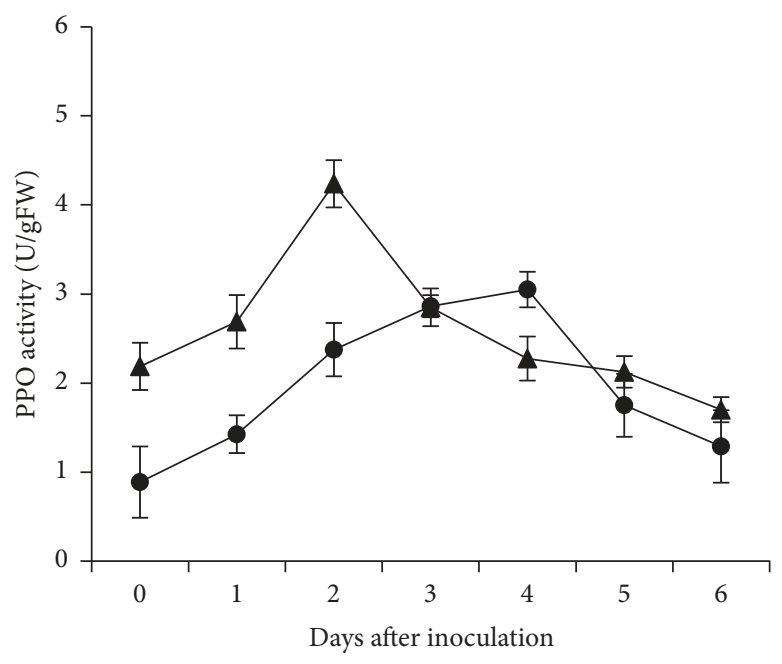

$\longrightarrow \mathrm{CK}$
$-\mathrm{Y} 16$

(A)

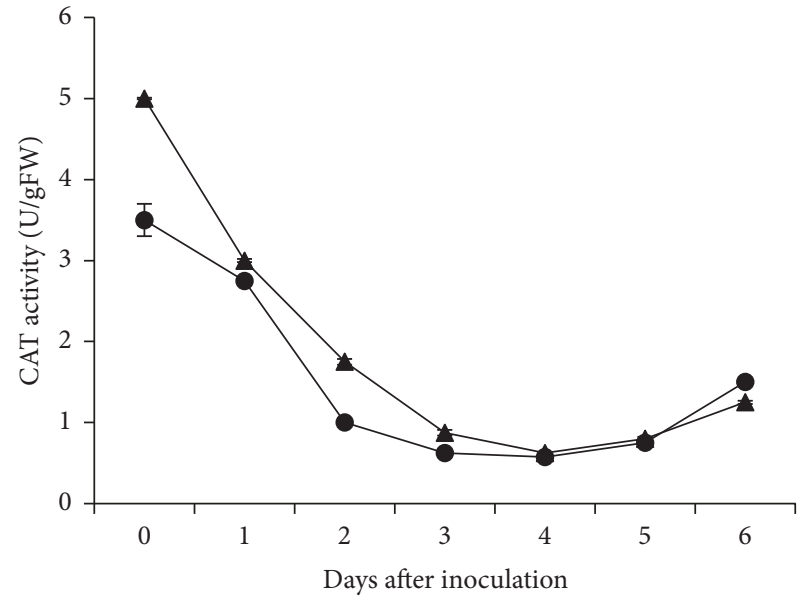

- $\mathrm{CK}$

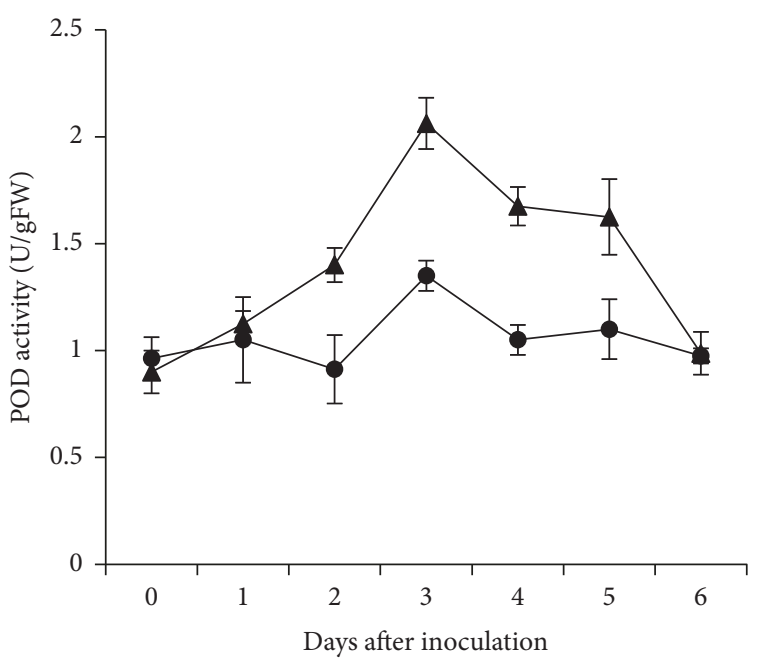

(B)

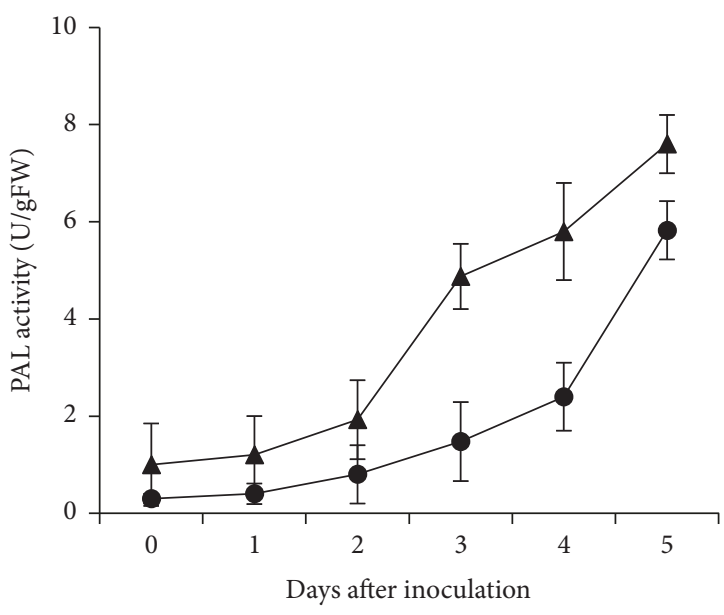

$-\mathrm{CK}$
$-\mathrm{Y} 16$

(C)

(D)

FIGURE 4: Effects of polyphenol oxidase (PPO) (A), peroxidase (POD) (B), catalase (CAT) (C), and phenylalanine ammonia lyase (PAL) (D) activities in apples treated with $S$. pararoseus Y16. Each value is the mean of two experiments. Bars represent standard errors.

was described as the capacity of the tissues to scavenge excess ROS and maintain ROS concentration at relatively low level [1]. Our results suggested that the CAT activity of apples was induced by S. pararoseus Y16 in this study; S. pararoseus Y16 improved CAT activity of apples, which may also be one of the reasons for enhancing the resistance ability of apples [24]. PAL is a key rate-limiting enzyme for the pathway of phenylpropanoid metabolites in fruits and vegetables, and it also could be used as a kind of important resistancerelated enzymes that contribute to the production of lignin, alkaloids, and other resistant substances. It can be seen from Figure 4(D) that the PAL activity of apple fruit in S. pararoseus Y16 treatment group was significantly higher than that of the control during the whole storage period, which indicated that it could induce the PAL activity of apples.
Pathogenesis-related (PR) family of proteins could inhibit the activity of pathogens and improve the disease resistance of fruits. In this article, the relative expression levels of defenserelated genes of apples induced by $S$. pararoseus Y16 were studied. The results showed that the expression levels of $P R-3$, $P R-4, P R-5$, and $P R-9$ on apples were increased when treated with $S$. pararoseus Y16. $P R-3$ and $P R-4$ encoding chitinase and $\beta$-1,3-glucanase, respectively, which had high expression levels of hydration enzymes in plants, could destroy the cell wall of fungi. Meanwhile, $P R-5$ belongs to the genes encoded by the sweet protein and has $\beta$-1,3-glucan binding activity, antitrypsin activity, kinase activity, and actin binding activity, indicating that its induced expression may be involved in the improvement of disease resistance to apples $[25,26] . P R-9$ is a peroxidase-encoding gene, involved in production of lignin 

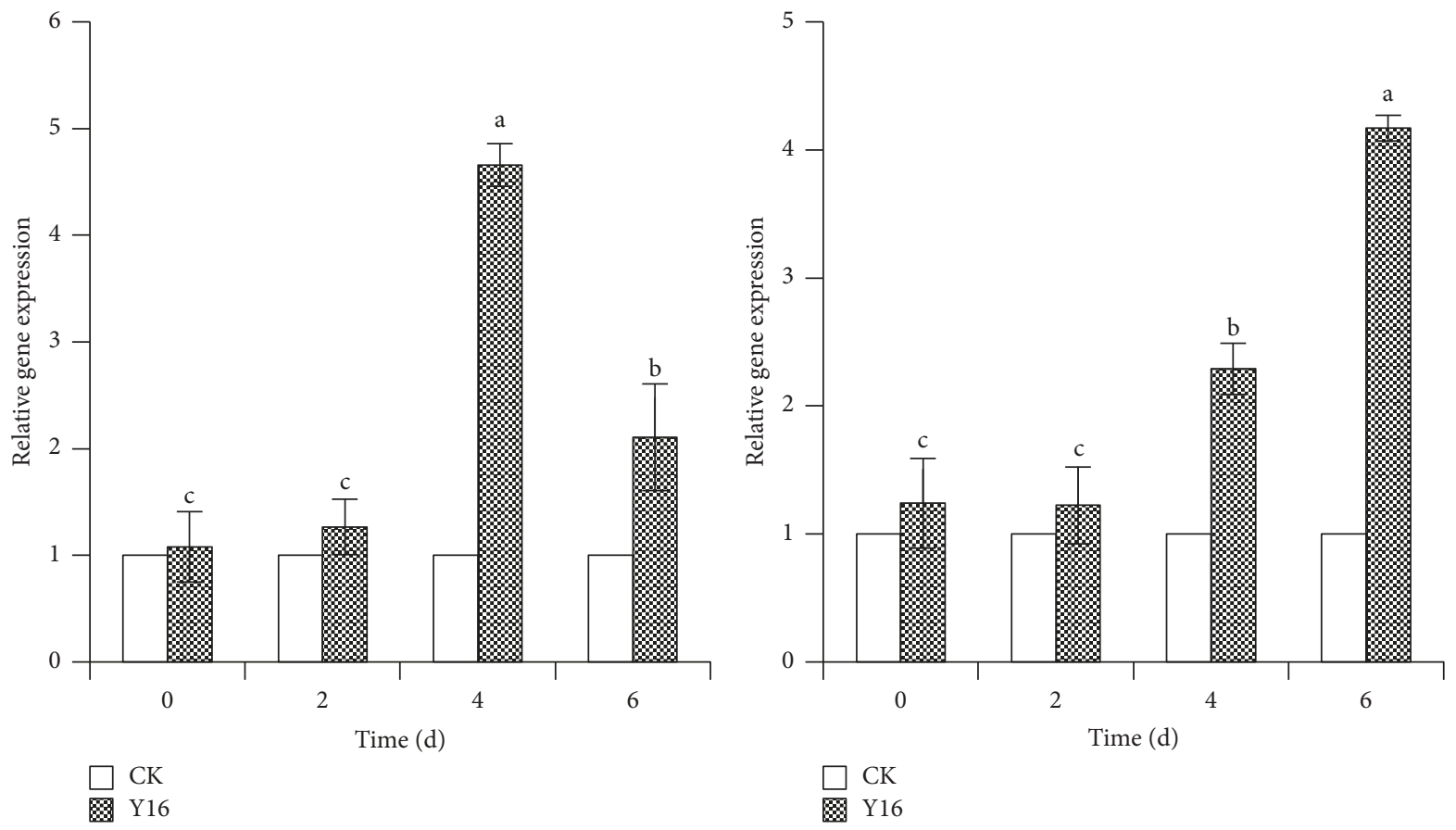

(A)

(B)
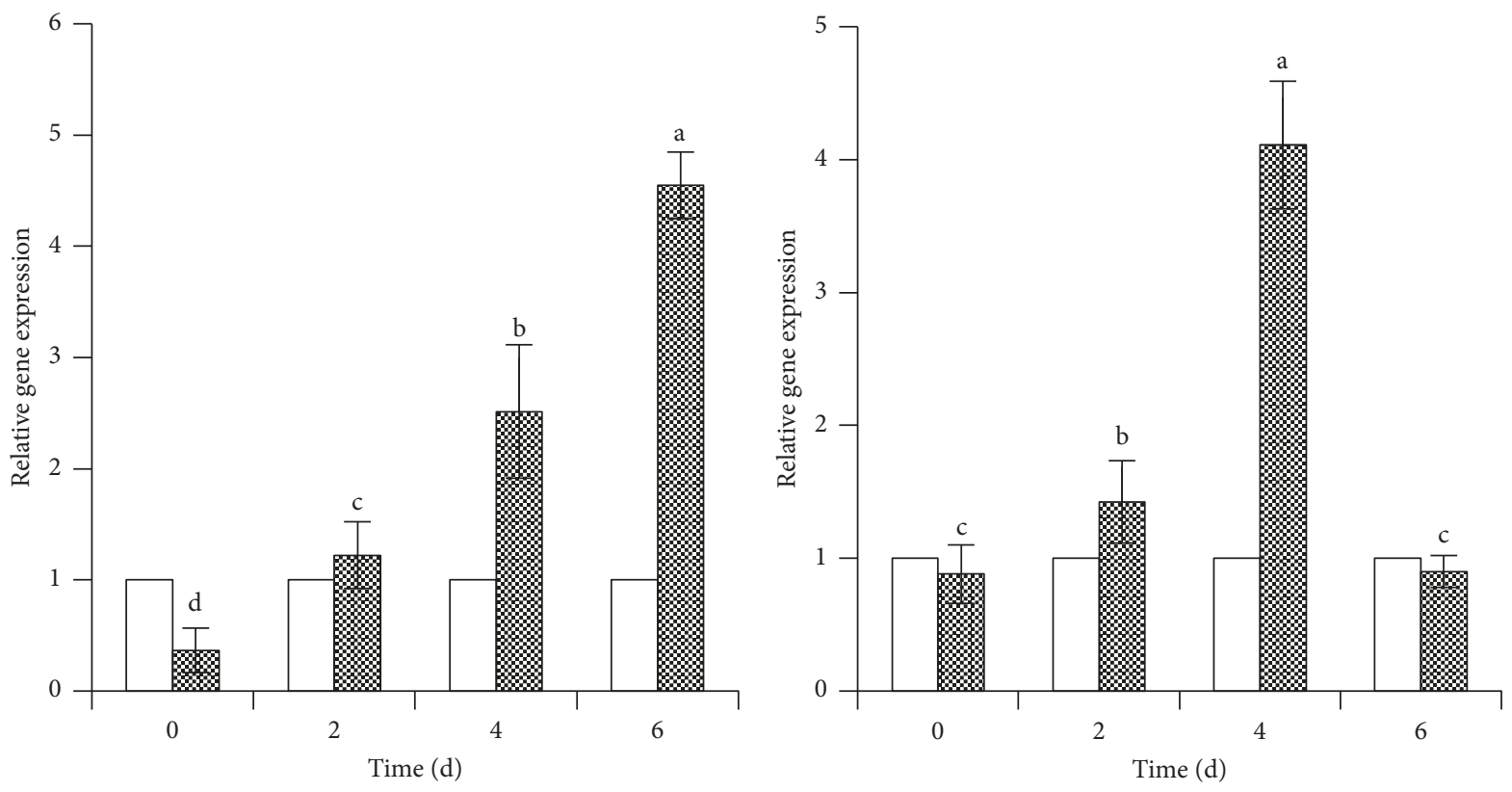

$\square \mathrm{CK}$

$\square \mathrm{CK}$

Y Y16

(C)

(D)

FIgURE 5: Relative expression levels of (A) $P R-3$, (B) $P R-4$, (C) $P R-5$, and (D) $P R-9$ in apples treated with S. pararoseus Y16. MdActin was used as the internal control gene. Apples were treated with sterile distilled water as the control. Bars represent the standard error of the mean. Data in columns with the different letters are significantly different according to Duncan's multiple range test at $P<0.05$.

that enhances resistance to pathogens [27]. These results indicated that $S$. pararoseus Y16 has great biocontrol effects on postharvest blue mold decay of apples, largely because $S$. pararoseus Y16 could induce the expression levels of defenserelated genes in apples and improve its resistance, which also explains the mechanism of $S$. pararoseus Y16 inducing the disease resistance of the apples at the transcription levels of the genes.

In conclusion, the involved possible mechanism of $S$. pararoseus Y16 controlling blue mold decay of apples mainly 
includes the following: (1) S. pararoseus Y16 competed with $P$. expansum for space and nutrition, which is the dominant flora, inhibiting the growth of pathogens; (2) S. pararoseus Y16 can significantly induce the activities of PPO, POD, CAT, and PAL in the resistance of apples in vivo and improve the disease resistance of apple fruits; (3) S. pararoseus Y16 induced the expression levels of defense-related genes in apples and improved the resistance of fruits. Further studies are needed to evaluate the effect of $S$. pararoseus Y16 as biocontrol agent against postharvest diseases of other fruits.

\section{Additional Points}

Practical Applications. Biological control with antagonistic yeasts has emerged as a promising way to reduce synthetic fungicide usage. Many microbial antagonists have been reported to control several pathogens on different fruits and vegetables. This study investigated the biocontrol of postharvest diseases of apple fruits by S. pararoseus Y16, which was isolated by our laboratory, and the mechanism of $S$. pararoseus controlling of postharvest diseases. It not only enriches the resource library of strains, but also provides theoretical basis for the practical application of using antagonistic yeasts to control the postharvest diseases of fruits.

\section{Conflicts of Interest}

The authors declare that there are no conflicts of interest.

\section{Acknowledgments}

This research was supported by the National Natural Science Foundation of China (31701971, 31571899) and 333 High-Level Personnel Training Project of Jiangsu Province (BRA2017442).

\section{References}

[1] G. K. Mahunu, H. Zhang, Q. Yang, X. Zhang, D. Li, and Y. Zhou, "Improving the biocontrol efficacy of Pichia caribbica with phytic acid against postharvest blue mold and natural decay in apples," Biological Control, vol. 92, pp. 172-180, 2016.

[2] A. El ghaouth, M. Wisniewski, C. L. Wilson, and S. Droby, "Biologically based technology for the control of postharvest diseases of fruits and vegetables," in Microbial Food Contamination, CRC Press, 2000.

[3] A. C. da Rocha Neto, C. Luiz, M. Maraschin, and R. M. Di Piero, "Efficacy of salicylic acid to reduce Penicillium expansum inoculum and preserve apple fruits," International Journal of Food Microbiology, vol. 221, pp. 54-60, 2016.

[4] J. Cao, H. Zhang, Q. Yang, and R. Ren, "Efficacy of Pichia caribbica in controlling blue mold rot and patulin degradation in apples," International Journal of Food Microbiology, vol. 162, no. 2, pp. 167-173, 2013.

[5] L. Zhao, H. Zhang, H. Lin, X. Zhang, and X. Ren, "Effect of trehalose on the biocontrol efficacy of Pichia caribbica against post-harvest grey mould and blue mould decay of apples," Pest Management Science, vol. 69, no. 8, pp. 983-989, 2013.

[6] D. Zhang, H. Wang, Y. Hu, and Y. Liu, "Chitosan controls postharvest decay on cherry tomato fruit possibly via the mitogen-activated protein kinase signaling pathway," Journal of Agricultural and Food Chemistry, vol. 63, p. 7399, 2015.

[7] S. Droby, M. Wisniewski, D. Macarisin, and C. Wilson, “Twenty years of postharvest biocontrol research: Is it time for a new paradigm?" Postharvest Biology and Technology, vol. 52, no. 2, pp. 137-145, 2009.

[8] D. R. Fravel, "Commercialization and implementation of biocontrol," Annual Review of Phytopathology, vol. 43, pp. 337-359, 2005.

[9] H. Morales, V. Sanchis, J. Usall, A. J. Ramos, and S. Marín, "Effect of biocontrol agents Candida sake and Pantoea agglomerans on Penicillium expansum growth and patulin accumulation in apples," International Journal of Food Microbiology, vol. 122, no. 1-2, pp. 61-67, 2008.

[10] R. Li, H. Zhang, W. Liu, and X. Zheng, "Biocontrol of postharvest gray and blue mold decay of apples with Rhodotorula mucilaginosa and possible mechanisms of action," International Journal of Food Microbiology, vol. 146, no. 2, pp. 151-156, 2011.

[11] R. Zhu, T. Yu, S. Guo, H. Hu, X. Zheng, and P. Karlovsky, "Effect of the yeast Rhodosporidium paludigenum on postharvest decay and patulin accumulation in apples and pears," Journal of Food Protection, vol. 78, no. 1, pp. 157-163, 2015.

[12] Q. Li, Biocontrol of Postharvest Diseases of Table Grapes by Sporidiobolus Pararoseus Y16 and Study on Its Mechanism and Preparation, Jiangsu University, China, 2017.

[13] Q. Li, C. Li, P. Li et al., "The biocontrol effect of Sporidiobolus pararoseus Y16 against postharvest diseases in table grapes caused by Aspergillus niger and the possible mechanisms involved," Biological Control, vol. 113, pp. 18-25, 2017.

[14] W. Li, H. Zhang, P. Li et al., "Biocontrol of postharvest green mold of oranges by Hanseniaspora uvarum Y3 in combination with phosphatidylcholine," Biological Control, vol. 103, pp. 3038, 2016.

[15] C. Li, H. Zhang, Q. Yang, M. G. Komla, X. Zhang, and S. Zhu, "Ascorbic acid enhances oxidative stress tolerance and biological control efficacy of Pichia caribbica against postharvest blue mold decay of apples," Journal of Agricultural and Food Chemistry, vol. 62, no. 30, pp. 7612-7621, 2014.

[16] M. Mohammadi and H. Kazemi, "Changes in peroxidase and polyphenol oxidase activities in susceptible and resistant wheat heads inoculated with Fusarium graminearum and induced resistance," Journal of Plant Sciences, vol. 162, no. 4, pp. 491-498, 2002.

[17] Y. S. Wang, S. P. Tian, Y. Xu, G. Z. Qin, and H. Yao, “Changes in the activities of pro- and anti-oxidant enzymes in peach fruit inoculated with Cryptococcus laurentii or Penicillium expansum at 0 or $20^{\circ} \mathrm{C}$," Postharvest Biology and Technology, vol. 34, no. 1, pp. 21-28, 2004.

[18] H. Zhang, L. Ge, K. Chen, L. Zhao, and X. Zhang, "Enhanced biocontrol activity of rhodotorula mucilaginosa cultured in media containing chitosan against postharvest diseases in strawberries: Possible mechanisms underlying the effect," Journal of Agricultural and Food Chemistry, vol. 62, no. 18, pp. 42144224, 2014.

[19] M. Bar-Shimon, H. Yehuda, L. Cohen et al., "Characterization of extracellular lytic enzymes produced by the yeast biocontrol agent Candida oleophila," Current Genetics, vol. 45, no. 3, pp. 140-148, 2004.

[20] S. K. Bencheqroun, M. Bajji, S. Massart, M. Labhilili, S. E. Jaafari, and M. H. Jijakli, "In vitro and in situ study of postharvest apple blue mold biocontrol by Aureobasidium pullulans: 
Evidence for the involvement of competition for nutrients," Postharvest Biology and Technology, vol. 46, no. 2, pp. 128-135, 2007.

[21] R. R. Sharma, D. Singh, and R. Singh, "Biological control of postharvest diseases of fruits and vegetables by microbial antagonists: a review," Biological Control, vol. 50, no. 3, pp. 205221, 2009.

[22] G. L. Farkas and M. A. Stahmann, "On the nature of changes in peroxidase isoenzymes in bean leaves infected by southern bean mosaic virus," Journal of Phytopathology, vol. 56, p. 669, 1966.

[23] X. Qin, H. Xiao, C. Xue et al., "Biocontrol of gray mold in grapes with the yeast Hanseniaspora uvarum alone and in combination with salicylic acid or sodium bicarbonate," Postharvest Biology and Technology, vol. 100, pp. 160-167, 2015.

[24] M. C. Mehdy, "Active oxygen species in plant defense against pathogens," Plant Physiology, vol. 105, no. 2, pp. 467-472, 1994.

[25] D. Liu, X. He, W. Li, C. Chen, and F. Ge, "Molecular cloning of a thaumatin-like protein gene from Pyrus pyrifolia and overexpression of this gene in tobacco increased resistance to pathogenic fungi," Plant Cell, Tissue and Organ Culture, vol. 111, no. 1, pp. 29-39, 2012.

[26] J.-J. Liu, R. Sturrock, and A. K. M. Ekramoddoullah, “The superfamily of thaumatin-like proteins: Its origin, evolution, and expression towards biological function," Plant Cell Reports, vol. 29, no. 5, pp. 419-436, 2010.

[27] L. C. Van Loon, M. Rep, and C. M. J. Pieterse, "Significance of inducible defense-related proteins in infected plants," Annual Review of Phytopathology, vol. 44, pp. 135-162, 2006. 


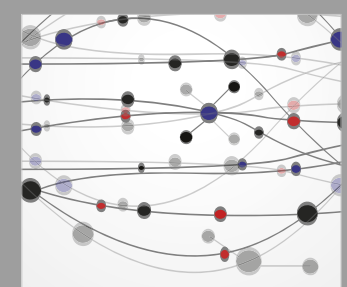

The Scientific World Journal
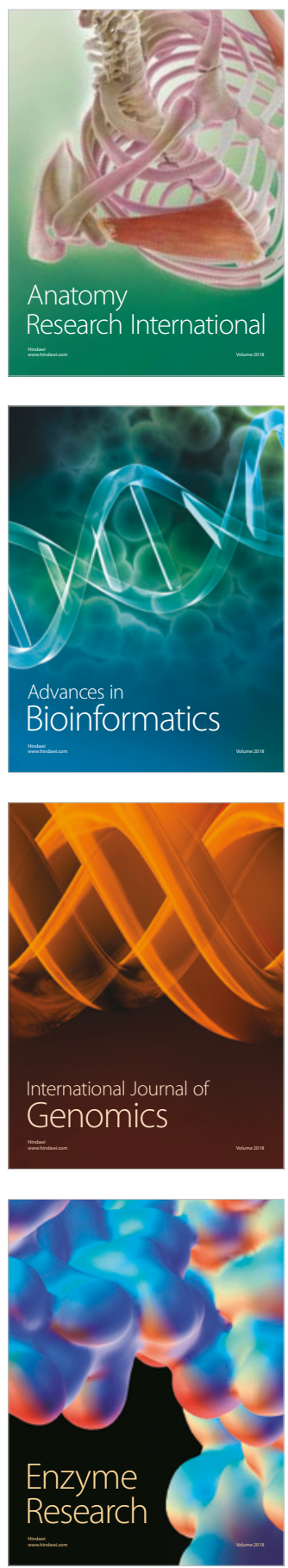
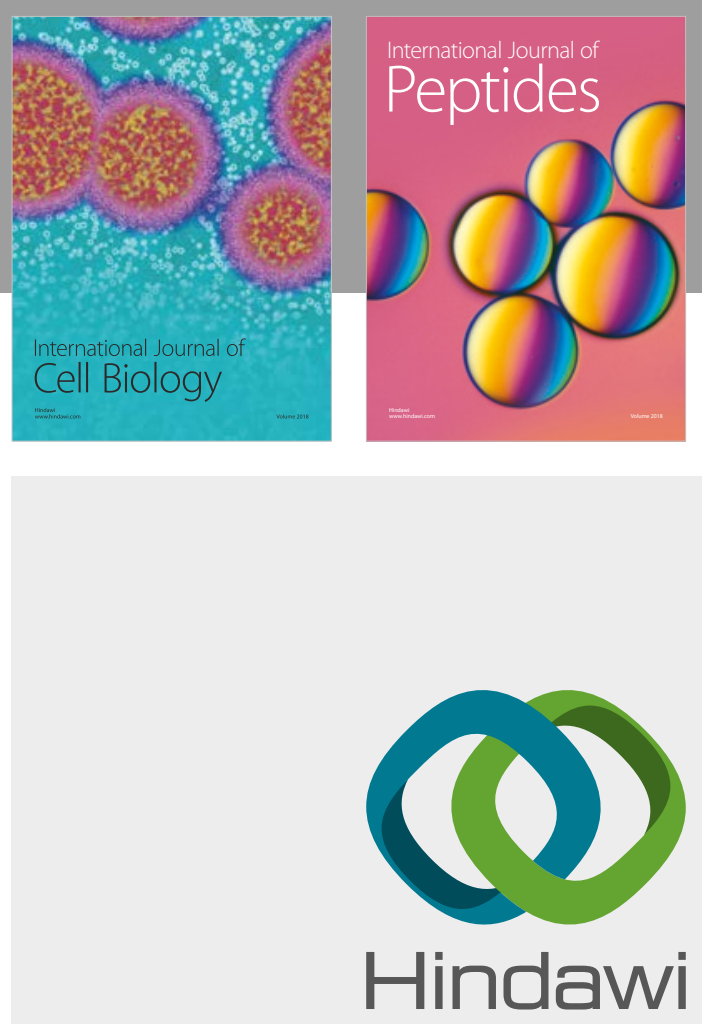

Submit your manuscripts at

www.hindawi.com
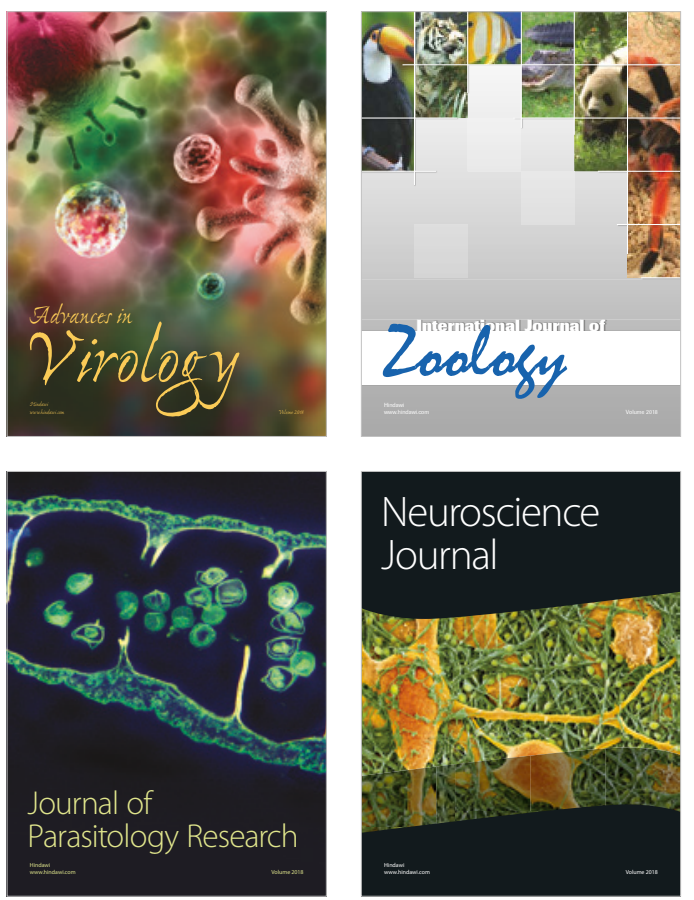
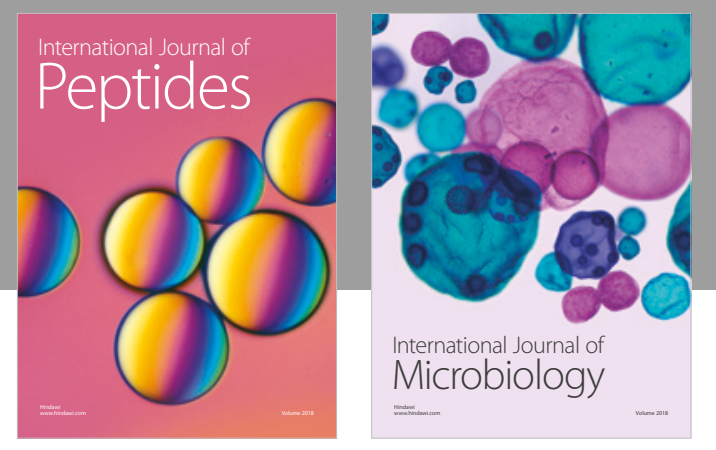

nternational Journal of Microbiology
Journal of
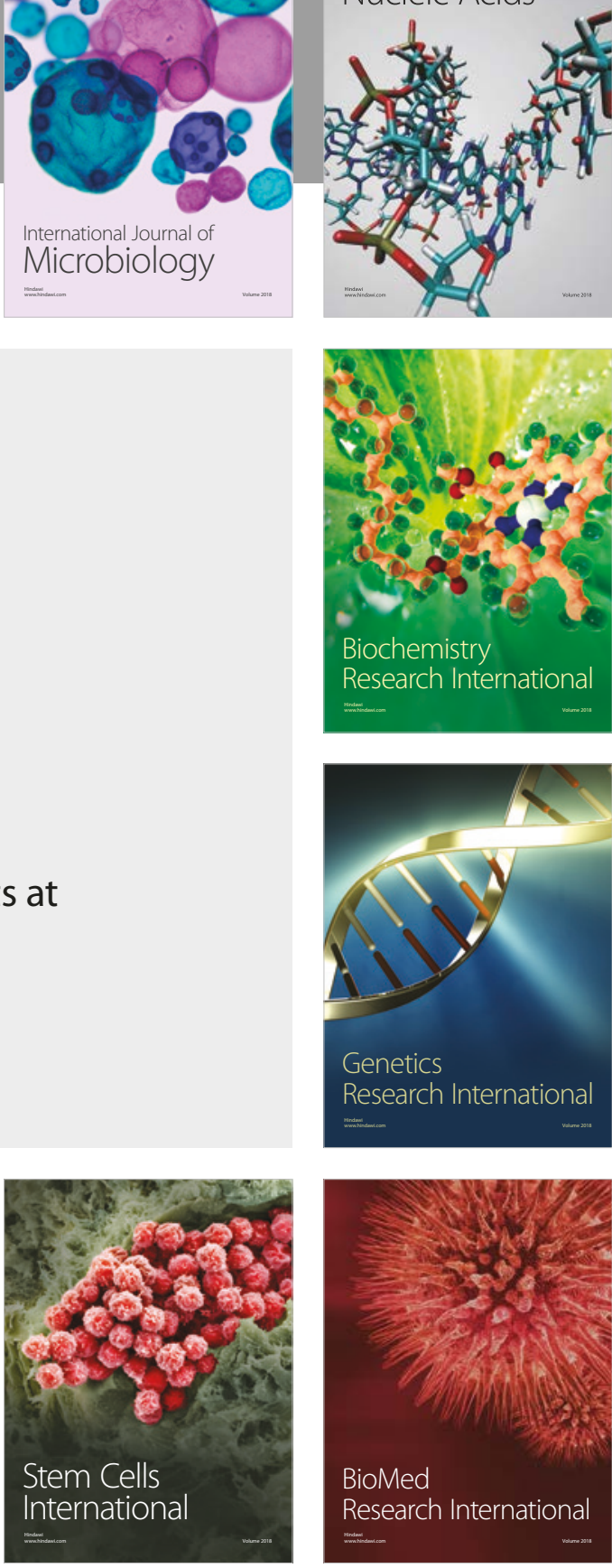
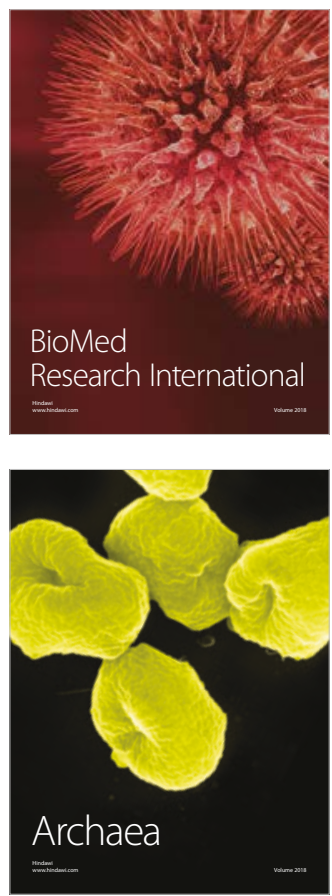